\title{
Fóruns no ambiente Teleduc: reflexões sobre o papel dos mediadores e estratégias de gerenciamento de debates
}

Forums in the TelEduc Learning Environment: Reflections on the Mediators'Role and on Debate-Management Strategies

Ludmila Belotti Andreu Funo*

Universidade Estadual Paulista

São José do Rio Preto - São Paulo / Brasil

Anna-Katharina Elstermann**

Universidade Estadual Paulista

Assis - São Paulo / Brasil

Micheli Gomes de Souza***

Universidade Estadual Paulista

São José do Rio Preto - São Paulo / Brasil

RESUMO: Fóruns de discussão online têm sido largamente utilizados em cursos a distância ou semipresenciais. Nesses contextos, a atuação do mediador ou tutor é de suma importância para o sucesso na aprendizagem. No presente artigo, discutimos alguns estudos sobre os papéis dos mediadores em contextos de EAD. Confrontamos esses saberes com a análise de um estudo de caso de base qualitativa, no qual foram investigadas as estratégias de gerenciamento de debates utilizadas por mediadores em fóruns de discussão na plataforma TelEduc. Finalmente, propomos um quadro reflexivo sobre estratégias de gerenciamento de fóruns em plataformas virtuais de aprendizagem.

PALAVRAS-CHAVE: fóruns de discussão; estratégias de mediação; educação online.

\footnotetext{
*1bandreu@hotmail.com

**anna@assis.unesp.br

***souza.micheli@hotmail.com
} 


\begin{abstract}
Online discussion forums have been widely used in internetmediated courses and blended courses. In these learning contexts, the mediator's (or tutor's) role in supporting successful learning is of considerable importance. Firstly, the present article discusses some studies in which the mediator's role in online learning environments is emphasized. Secondly, we use this discussion to support our qualitative case-study analysis, in which we investigated mediators' debate-management strategies in TelEduc virtual forums. Lastly, we propose a reflective framework about management strategies in forums in virtual learning platforms.
\end{abstract}

KEYWORDS: discussions forums; mediation strategies; online education.

\title{
1. Introdução
}

O TelEduc é um software livre que pode ser qualificado como um Course Management System, ${ }^{1}$ um Learning Management System, ${ }^{2}$ ou ainda Virtual Learning Environment, ${ }^{3}$ capaz de subsidiar ferramentas virtuais elaboradas com o propósito de assistir práticas telecolaborativas de aprendizagem.

A plataforma TelEduc ${ }^{4}$ foi desenvolvida pelo Nied (Núcleo de Informática Aplicada à Educação) sob a orientação da Profa. Dra. Heloísa Vieira da Rocha, do Instituto de Computação da Unicamp (Universidade Estadual de Campinas) e é utilizada por diversas instituições de ensino superior para a promoção de cursos a distância, semipresenciais, ou como um contexto de interação complementar em cursos presenciais.

Cabe ressaltar que, até o mês de setembro de 2007, cinco anos após sua disponibilização, o TelEduc já era utilizado por mais de três mil instituiçóes públicas e privadas do Brasil e de outros países. Essa popularização demonstra a expansão da utilização desse tipo de tecnologia e a relevância de mantermos nossos olhares atentos às dinâmicas interativas e pedagógicas que emergem desses contextos.

O TelEduc disponibiliza em sua interface recursos como: agenda (página inicial, onde se postam as atividades previstas para um determinado período), material de apoio (textos digitalizados diversificados e outros

\footnotetext{
${ }^{1}$ Expressão também conhecida pela sigla CMS ou, em português, sistema de gerenciamento de cursos.

2 Sistema De Gerenciamento de Aprendizagem.

${ }^{3}$ Ambiente Virtual de Aprendizagem.

${ }^{4}$ Para saber mais sobre o TelEduc, acesse:<http://hera.nied.unicamp.br/>. Acesso em: 30 jul 2014.
} 
materiais relevantes disponibilizados pelo formador), ferramentas para a formulação de enquetes, mural de avisos, fóruns de discussão, diários de bordo, salas de bate-papo e portfólios, por exemplo.

Dentre os instrumentos supracitados, o grande interesse deste artigo reside nos fóruns de discussão, mais especificamente nas abordagens/ estratégias que tutores (ou responsáveis pelo processo de mediação pedagógica) utilizam para gerenciar as discussóes nesses ambientes subsidiados pela plataforma TelEduc.

Um fórum de internet ou fórum de discussão é um espaço virtual para a troca e o arquivamento de pensamentos, opiniōes e experiências dos seus usuários. A comunicação entre eles normalmente acontece de forma assíncrona, ou seja, não em tempo real, como no caso dos fóruns analisados.

A forma como o fórum é utilizado depende de vários fatores, dentre eles o tipo de curso oferecido, o público-alvo, os objetivos dos formadores para com as atividades dos fóruns (avaliativas ou não), podendo ser tanto um espaço para os alunos tirarem suas dúvidas, quanto um espaço para discussão e compartilhamento de ideias entre alunos e entre alunos e tutores (ou mediadores), de modo telecolaborativo.

Segundo Bremer (2004), os fóruns na internet desenvolveram-se como um meio de comunicação muito importante no âmbito dos cenários de e-learning. Eles possibilitam a interação tanto de grupos pequenos quanto de grupos grandes.

Bachmann et al. (2002) identificam diversos papéis para um fórum, tendo em vista três cenários de e-learning diferentes: (a) no ensino presencial, fóruns podem contribuir para consolidar a aprendizagem em sala de aula. Em cursos do tipo (b) blended-learning (semipresencial), a importância dos recursos disponibilizados na plataforma virtual é grande, podendo ser atribuído aos fóruns o caráter de parte integral e imprescindível da estrutura geral do curso. Em cenários (c) completamente online, por sua vez, eles podem tornar-se o único ou o principal meio de comunicação. (BACHMANN, DITTLER, LEHMAN, GLATZ \& RÖSEL, 2002).

Além de basearem-se na comunicação escrita, os fóruns diferenciamse de outros meios de comunicação online como o chat (bate-papo) ou videoconferências por causa da sua forma assíncrona, ou seja, os participantes contribuem com seus comentários em horários e dias diferentes, de acordo com a disponibilidade de tempo de cada um (BREMER, 2004).

Fóruns servem especialmente para processos de comunicação complexos, nos quais a divergência de opiniōes é possível ou desejada 
(FILK, 2001). Nesse sentido, em discussões no contexto de fóruns online, aspectos aparentemente contraditórios de um mesmo assunto podem ser considerados pelos participantes como expressão da pluralidade de ênfases possíveis deflagradas por um tema complexo e trazidas para o enriquecimento da discussão.

Bremer (2004) também ressalta as várias possibilidades de uso dos fóruns virtuais: abrir um debate, elucidar a complexidade de um tema, abordar opiniōes divergentes sobre um assunto, desenvolver atividades introdutórias de um curso, utilizadas para que os cursistas se conheçam melhor ou para elucidar as expectativas e crenças de seus colaboradores sobre um determinado tema, bem como no decorrer ou final de um ciclo de atividades pedagógicas, como ferramenta de avaliação, autoavaliação, ou de elaboração de trabalhos em grupo (BREMER, 2004).

Considerando as especificidades dos fóruns como ambiente de interação pedagógica, exploramos, a seguir, o papel dos mediadores e, na análise de dados, as estratégias utilizadas por mediadores em dez fóruns de discussão de um curso semipresencial de formação continuada de professores.

\section{Mediação}

Segundo Funo (2014, em preparação), mediação é um termo guardachuva. Conforme Vygotsky (1984), em sua obra Formação social da mente, a mediação ocorreria no espaço engendrado entre "a distância entre o nível de desenvolvimento atual determinado pela resolução independente de problemas e o nível de desenvolvimento potencial determinado pela resolução de problemas sob orientação ou em colaboração com parceiros mais capazes" (VYGOTSKY, 1984, p.211).

Ou seja, em um espaço chamado de zona de desenvolvimento proximal, ou ZDP, há distinção de dois níveis de desenvolvimento do aprendiz, o real e o potencial. O primeiro (real) caracteriza-se pela habilidade do aprendiz de realizar tarefas de modo independente. O segundo (potencial) caracteriza-se pelas funções potenciais que esse aprendiz pode desempenhar com a ajuda de um parceiro que exerça o papel de especialista e lhe ofereça alguma forma de suporte.

Nesse contexto interpelativo que são os fóruns virtuais é possível que ocorra "mediação" e, como muitos interagentes estão envolvidos nesse contexto complexo, supõe-se que não necessariamente o docente intitulado mediador de fato o será. No entanto é ele quem se preocupa a priori em 
possibilitar um contexto favorável para que a aprendizagem e a mediação possam ocorrer, ou seja, para que scaffolding ou andaimes sejam construídos e possibilitem a transformação entre o que é nível real e o potencial de aprendizagem dos interagentes (FUNO, 2014, em preparação).

Assim, o conceito de mediação adotado neste artigo tem inspiração vigotskyana e pressupõe que aprendizagem e desenvolvimento são processos inter-relacionados e que podem sofrer alterações mediante o fenômeno de uma assistência (ou scaffolding) (FUNO, 2014, em preparação).

Outro pressuposto do conceito de mediação é que a aprendizagem pode ocorrer ao longo de nossas existências, embora não ocorra com a mesma plasticidade da infância, o que está de acordo com a leitura de Mitchell e Myles (1998), ao explicarem que, segundo a perspectiva sociocultural,

novos conceitos continuam a ser adquiridos através dos meios interacionais/ sociais, um processo que pode às vezes ser visivelmente constatado no curso da fala entre um especialista e um aprendiz. Esse processo de aprendizagem local e contextualizado chama-se microgênese e é central para a perspectiva sociocultural de aprendizagem de segunda língua (MITCHELL \& MYLES 1998, p.148).

Logo, o conceito de mediação é um construto teórico apoiado na crença da possibilidade de se expandir o conceito de zona de desenvolvimento proximal como pertinente para elucidar o desenvolvimento da aprendizagem e de aprendizes em diversas faixas etárias (FUNO, 2014, em preparação).

Ao evocar o conceito de mediação em contextos virtuais de aprendizagem, assume-se a possibilidade de que o aprendiz e/ou seu mediador são capazes de (a) reconhecer características de um dado estágio de aprendizagem; (b) perceber que essas características se transformam e, assim, concomitantemente, (c) notar que o aprendiz e a percepção dele e dos demais sobre seu desenvolvimento (autoavaliação) também são transformadas.

O que se medeia, ou a forma como a mediação acontece não é algo fixo nos contextos telecolaborativos, virtuais, ou presenciais de aprendizagem, ou seja, mudam os neófitos, mudam seus interagentes mais proficientes em um dado saber, mudam os objetivos pessoais de aprendizagem, as motivações, os mediadores, as culturas envolvidas, mudam as ferramentas e as possibilidades que intermedeiam a aprendizagem online, mudam as motivações e muda a demanda social, daí a dificuldade em comparar indícios deflagradores da mediação e do que se medeia dentre os muitos estudos sobre aprendizagem online tecidos até então (FUNO, 2014, em preparação). 


\section{O mediador em fóruns virtuais}

Mesmo diante do rápido progresso da educação a distância, ainda é possível encontrar perspectivas pedagógicas que concebem apenas a comunicação face-a-face como uma alternativa satisfatória para o desenvolvimento de atividades de ensino e aprendizagem (MILL, 2010).

Embora alguns sistemas de comunicação online ainda tenham muitas limitaçōes, a prática de debates em fóruns virtuais tem se mostrado profícua para o desenvolvimento de discussões colaborativas sobre temas complexos (BARROS \& SOUZA, 2011).

Para que a construção de conhecimento em contexto online ocorra a partir de processos de colaboração, interação e negociação de sentidos, a intervenção docente através da mediação virtual é crucial (SALMON, 2009). Por isso, é importante refletirmos sobre o papel que professores mediadores estão desempenhando em contextos telecolaborativos de aprendizagem.

Bawane e Spector (2009), em estudo feito nos Estados Unidos, exploraram o tema das competências e dos papéis desempenhados por tutores/mediadores em ambientes online de aprendizagem e, segundo esses autores, o profissional que exerce a mediação pedagógica virtual deve ser flexível, desempenhar um papel multidimensional e obter um leque amplo e diverso de competências técnicas, comunicativas e pedagógicas.

Bawane e Spector (2009) pontuam que vários pesquisadores se esforçaram em descrever os papéis desempenhados por mediadores online, incluindo, em geral, os papéis pedagógico, social, administrativo e técnico (BAWANE \& SPECTOR, 2009, p. 388). Depois de apresentar uma reflexão sobre as pesquisas acerca de mediação virtual entre os anos de 1995 até 2007, os autores enfatizam oito papéis relevantes para um mediador que atua em contextos online: (a) o papel ético, (b) o papel pedagógico, (c) o papel social, (d) o papel avaliador, (e) o papel de administrador, (f) o papel tecnológico, (g) o papel de conselheiro e (h) o papel de pesquisador (BAWANE \& SPECTOR, 2009, p. 390), conforme sintetizamos a seguir:

a) O papel ético, segundo os autores, diz respeito ao cumprimento das regras estabelecidas no ambiente virtual de um curso. Além disso, a constante busca por aprimoramento e atualização também é parte da ética em mediação;

b) O papel pedagógico, por sua vez, demanda dos mediadores competências para (b.1) o desenvolvimento e a implementação de estratégias de ensino, (b.2) o desenvolvimento de recursos de aprendizagem e (b.3) motivação; 
c) O papel social diz respeito às responsabilidades em (c.1) manter um ambiente cordial de aprendizagem, (c.2) desenvolver estratégias cordiais de resolução de conflitos, (c.3) prevenir comportamentos indesejáveis e facilitar a interação no grupo;

d) Como avaliador, o mediador precisa desenvolver a competência de (d.1) monitorar o progresso individual e do grupo, bem como (d.2) elaborar avaliações do curso, do programa, das ferramentas e atividades utilizadas no decorrer do curso, por exemplo;

e) No papel de administrador é necessário ao mediador (e.1) desenvolver estratégias para gerenciar o tempo e o rumo das discussōes, (e.2) desempenhar liderança e gerenciar o cumprimento das regras no ambiente virtual;

f) Como técnico, deve preocupar-se com o acesso, a seleção e o desenvolvimento de recursos tecnológicos apropriados;

g)Enquanto conselheiro, auxilia os participantes sugerindo medidas para a intensificação de desempenho, compartilhando saberes e guiando-os conforme suas necessidades;

h) Como pesquisador, deve preocupar-se com a prática de pesquisas dentro do ambiente virtual, questionando-se sobre a forma de coletar, interpretar e integrar os resultados de suas análises ao ensino e desenvolvimento do AVA como ambiente de interação pedagógica (BAWANE \& SPECTOR, 2009, p. 390).

Notamos que a divisão dos papéis não é estanque, mas didática, e que as práticas propostas por Bawane e Spector (2009), embora separadas sob rótulos distintos, estão emaranhadas.

Outros autores também refletiram sobre os papéis a serem desempenhados por mediadores virtuais, tais como Baran e Correia (2009). Segundo esses autores, o mediador talvez não consiga cumprir todas as responsabilidades que atualmente lhe são propostas e, assim, preencher todos os papéis discutidos pela literatura, por conta, sobretudo, das próprias limitaçôes (afinal, é um aprendiz em desenvolvimento também) e das limitações inerentes aos contextos pedagógicos nos quais atuam.

Conforme pudemos observar, a atuação pedagógica dos tutores ou mediadores virtuais tem sido tema de debate na literatura. Essa ênfase, engendrada por questóes sócio-históricas, nos permite refletir sobre a complexidade e os desafios desses profissionais. Assim, o presente artigo 
visa contribuir para esse debate, por meio do compartilhamento de reflexões embasadas em um estudo de caso sobre mediação em fóruns virtuais.

\section{Metodologia}

O presente trabalho orienta-se pelo paradigma interpretativista da pesquisa qualitativa e define-se como um estudo de caso de base qualitativa e interpretativista. Moita Lopes (1994) ao discorrer sobre as características da pesquisa qualitativa interpretativista coloca que "na visão interpretativista, os múltiplos significados que constituem as realidades só são passíveis de interpretação. É qualitativo e é o particular que interessa." (MOITA LOPES, 1994, p.332).

Considerando nosso contexto de pesquisa (fóruns de discussão no AVA TelEduc) e considerando também nosso objetivo (analisar os papéis que os mediadores desempenham no gerenciamento e na mediação de tais fóruns), buscamos, por meio de procedimentos interpretativos de análise, tecer reflexōes sobre as dinâmicas interativas entre mediadores e cursistas nos fóruns de discussão.

Não pretendemos, conforme nossas orientações metodológicas, produzir generalizaçóes a partir dos temas deflagrados, mas sim, pretendemos construir inteligibilidades acerca de uma realidade vivida. Desse modo, ao refletirmos sobre os dados do caso abordado, esperamos contribuir para as discussões sobre processos interativos de mediação em ambientes virtuais de aprendizagem (doravante AVAs), compartilhando reflexões embasadas em pesquisa.

\subsection{Contexto de pesquisa}

O contexto de pesquisa do trabalho em questão é um curso de formação continuada, semipresencial, desenvolvido para professores de espanhol dos CELs ${ }^{5}$ (Centro de Estudo de Línguas) de duas cidades do interior paulista.

O referido curso transcorreu durante o segundo semestre de 2009 e intitulou-se Formação do Professor para o Ensino/Aprendizagem de Linguas Estrangeiras em Tandem.

\footnotetext{
${ }^{5}$ Os Centros de Estudo de Línguas (CEL) são frutos de um programa da Secretaria da Educação do Estado de São Paulo (SEE-SP), que oferece ensino de línguas estrangeiras gratuito para alunos da rede pública estadual. Mais informaçôes: http://nev.incubadora. fapesp.br/portal/educacao/idiomas/cel. Acesso em: 26 mar. 2009.
} 
Seu objetivo principal era proporcionar a reflexão de seus cursistas (docentes de espanhol LE, vinculados a duas Diretorias de Ensino das regiões Noroeste e Sudoeste do estado de São Paulo) acerca da fundamentação, das práticas e das tecnologias de ensino e aprendizagem de idiomas nos contextos tandem e teletandem, além de discutir a formação docente para esses contextos colaborativos de aprendizagem.

O curso teve carga horária de 32 horas, divididas em 16 horas para a prática de teletandem ${ }^{6}$ e de atividades reflexivas no Teleduc e 16 horas divididas em quatro encontros presenciais. As reflexões dos cursistas, portanto, eram decorrentes de suas primeiras experiências de teletandem português-espanhol com professores uruguaios, das leituras teóricas, das discussões nos encontros presenciais e das interaçōes no ambiente virtual do TelEduc.

\subsection{Participantes}

Participaram dos fóruns 10 professores vinculados a uma Diretoria de Ensino do Noroeste paulista (PA), 13 professores de uma Diretoria da região Sudoeste (PS) e 10 mediadores pesquisadores ( $\mathrm{Mm}$ - mediadores mestrandos, que faziam pesquisa sobre teletandem durante o curso, e Mf - mediadores formadores, responsáveis pelo gerenciamento e módulos do curso).

\section{QUADRO 1}

Participantes de pesquisa

\begin{tabular}{|l|l|}
\hline \multicolumn{2}{|c|}{ Participantes do estudo } \\
\hline $\begin{array}{l}\text { Mediadores do AVA e formadores do curso de extensão } \\
\text { semipresencial que serve de contexto para a presente } \\
\text { pesquisa }\end{array}$ & $\begin{array}{l}\text { Mm (mediadores mestrandos, Mm1, Mm2 e } \\
\text { Mm3) e Mf (Mediadores vinculados formalmente } \\
\text { à universidade que subsidia o curso são Mf1, Mf2. } \\
\text { Mf3. Mf4, Mf5, Mf6 e Mf7). }\end{array}$ \\
\hline $\begin{array}{l}\text { Cursistas (professores matriculados no referido curso } \\
\text { de extensão e que colaboraram para o presente estudo). }\end{array}$ & $\begin{array}{l}\text { PA1, PA2, PA3, PA4, PA5, PA6, PA7, PA8, PA9, } \\
\text { PA10, PS11, PS12, PS13, PS14, PS15, PS16, PS17, } \\
\text { PS18, PS19, PS20, PS21, PS22, PS23. }\end{array}$ \\
\hline
\end{tabular}

Fonte:Elaborado pelas autoras.

\footnotetext{
${ }^{6}$ Para mais informaçôes, acesse: <www.teletandembrasil.org>. Acesso em: 30 jul. 2014.
} 


\subsection{Material documentário}

Compóe o corpus do presente estudo (a) a compilação dos fóruns virtuais desenvolvidos para o contexto estudado como dados focais, e (b) a transcriçãoo de gravaçôes em áudio dos encontros presenciais como dados secundários. O papel dos dados secundários é o de apoiar a análise dos dados focais, possibilitando confirmar ou refutar hipóteses de interpretação.

\section{Análise}

Nesta seção, apresentamos a análise dos dados que foram extraídos de fóruns virtuais, subsidiados pela plataforma TelEduc. Primeiro, abordaremos a participação dos mediadores nos vários fóruns abertos no TelEduc para a discussão com os participantes do curso. Em um segundo passo, observamos mais detalhadamente as abordagens utilizadas pelos formadores e mediadores para intervir durante os debates dos fóruns. Cabe ressaltar que os fóruns estavam vinculados a um curso no qual a prática de teletandem era enfocada.

\subsection{Os fóruns e a participação dos mediadores}

Apresentamos aqui os trechos contendo exemplos de como foram feitas as propostas de debate nos fóruns postados na plataforma TelEduc. Foram realizados dez fóruns no transcorrer do curso de formação continuada Formação de professores para o Ensino e Aprendizagem em Tandem na referida plataforma:

\section{QUADRO 2}

Fóruns e data de abertura dos mesmos

\begin{tabular}{|c|c|c|}
\hline \multicolumn{2}{|c|}{ Fórum } & Data da abertura dos fóruns \\
\hline 1 & Um teletandem para meus alunos & $16 / 05 / 2009$ \\
\hline 2 & Minhas experiências de Teletandem & $16 / 05 / 2009$ \\
\hline 3 & Refletir e Compartilhar & $29 / 05 / 2009$ \\
\hline 4 & Acordos & $31 / 05 / 2009$ \\
\hline 5 & E-mails para “quebra de gelo" & $31 / 05 / 2009$ \\
\hline 6 & Autonomia & $05 / 07 / 2009$ \\
\hline 7 & A tecnologia e a formação em serviço I & $14 / 07 / 2009$ \\
\hline 8 & A tecnologia e a formação em serviço II & $14 / 07 / 2009$ \\
\hline 9 & Experiência Intercultural & $21 / 07 / 2009$ \\
\hline 10 & Por que algumas parcerias “dão certo" e outras não? & $22 / 07 / 2009$ \\
\hline
\end{tabular}

Fonte:Elaborado pelas autoras. 
Os fóruns Um teletandem para meus alunos e Minhas experiências de teletandem foram os dois primeiros debates propostos no curso. Esses fóruns surgiram com a necessidade de dar continuidade às discussões iniciadas durante o primeiro encontro presencial, aprofundando as trocas de experiências sobre a prática do teletandem que lá haviam sido iniciadas e prolongando o debate sobre: (a) os múltiplos modos pelos quais os participantes do curso vislumbravam a apresentação do teletandem para seus alunos em seus contextos de trabalho; e (b) suas próprias experiências ao praticar teletandem.

Isso é o que demonstram os fragmentos a seguir, transcritos a partir da gravação em áudio feita do primeiro encontro presencial, no qual os formadores Mf6, Mf7 e Mf1 discorrem sobre o acontecimento dos primeiros fóruns:

eu só queria dizer que é um assunto que começa agora que não esta/não estamos fechando estamos apenas começando e que nós vamos colocar dois fóruns no TelEduc pra participar/continuar essa discussão ao longo do curso. (Mf7, primeiro encontro presencial, 15/05/2009).

como a (nome Mf7) disse agora vocês devem participar do fórum (+) entrem no teleduc já na parte do fórum pra vocês continuarem a discutir essas questôes. (Mf6, primeiro encontro presencial, 15/05/2009).

é a participação desse fórum eu acho que não há tanta necessidade de ser GRANDES horas nisso não você entra dez minutos dá uma leitura naquilo lá, depois entra no outro dia adiciona alguma coisa ou responde alguma coisa a alguém $(+)$ tá ok?. (Mf1, primeiro encontro presencial, $15 / 05 / 2009)$.

As propostas de discussão feitas para os dois primeiros fóruns demonstram uma preocupação com a necessidade de familiarizar os participantes do curso de formação continuada com a prática enunciativa pertinente a esse contexto de debates e com as trocas de conhecimentos, conforme podemos observar nos trechos a seguir:

Neste fórum, você vai poder colocar e trocar: reflexōes, dúvidas e propostas concretas sobre a organização de parcerias de teletandem para alunos do ensino médio - meus alunos:RESPONDA à mensagem PARA CONTINUAR o assunto. CRIE uma mensagem, PARA PROPOR 
um novo assunto. Leve para frente os assuntos propostos! (Mf7, Um teletandem para meus alunos).

Neste fórum, você vai poder colocar e trocar: Reflexóes, do ponto de vista profissional, sobre o que acontece no meu teletandem. RESPONDA à mensagem PARA CONTINUAR o assunto. CRIE uma mensagem, PARA PROPOR um novo assunto. Leve para frente os assuntos propostos! (Mf7, Minhas experiências de teletandem).

O sentido das propostas de debate não é o de restringir as possibilidades de interação ou o teor das postagens (embora também faça isso), mas é o de situar os cursistas num contexto interativo onde "responder as mensagens" de seus colegas, dando "continuidade" à discussão que se inicia (ou já em andamento) e "criar" novas mensagens sempre que houver a percepção da necessidade de se discutir um novo tema, são práticas desejáveis.

Os direcionamentos da introdução dos fóruns materializam estratégias interacionais cujo propósito é otimizar o aproveitamento pedagógico que os alunos podem ter no uso dessa ferramenta, pois, por exemplo, ajudam esses alunos a identificarem o tema e o objetivo dos debates.

Nos trechos transcritos, há indícios de que exista uma experiência prévia de Mf12 que levou esse formador à percepção de que era necessário inserir informações extras (que não as já apresentadas sobre cada uma das ferramentas no próprio site do TelEduc) nas propostas dos fóruns acerca de como interagir de modo eficiente para a construção de saberes nesse contexto.

A tentativa pode ter sido a de "poupar tempo" para os aprendizes e evitar um extenso monólogo nos fóruns, em que cada participante postaria a sua observação e não se daria conta das vantagens que a interação com os colegas poderia trazer para seu aprendizado.

Algo muito parecido com o exemplo supracitado ocorre no fórum Refletir e Compartilhar, o terceiro fórum postado na plataforma TelEduc durante o curso de formação ao qual este estudo está atrelado:

Descreva suas impressões até o momento e ao longo da próxima semana procure reagir às respostas de seus colegas e intervenções dos professores/ orientadores. Lembre-se de que esse espaço não se limita às respostas, mas sim às reflexōes, avaliações e reações críticas de sua experiência presencial contrastada ao ambiente virtual. Pergunta-chave: Que tipo de inquietaçôes pedagógicas o curso tem proporcionado considerando a sua vivência de ensino/aprendizagem? (MfG, Refletir e compartilhar). 
Note que, no excerto supracitado, além de diretrizes semelhantes às dos fóruns anteriores ("Descreva suas impressōes"; "procure reagir às respostas de seus colegas e intervenções dos professores/orientadores"; "Lembre-se de que esse espaço não se limita às respostas, mas sim às reflexões"), Mf6 salienta o tema da discussão propondo-o sob a forma de questionamento e acrescentando-lhe anteriormente a expressão "pergunta-chave", que reforça a ideia de que a pergunta que se segue é fundamental para o desenvolvimento das atividades nesse fórum.

Outros dois fóruns que chamam a atenção pela maneira como foram propostos são o sétimo e o oitavo (A tecnologia e a formação continuada I $e$ II), por trazerem perguntas embasadas na leitura dos portfólios que os participantes do curso estavam elaborando acerca da própria aprendizagem com a prática do teletandem.

A partir da leitura dos portfólios, comecei a refletir sobre os seguintes pontos: Vocês percebem a troca de papéis durante as interações de teletandem? Como vocês se sentem? Como ocorre a liberdade de gerenciar as sessões de teletandem? Esses dois aspectos, a troca de papéis e a liberdade de gerenciar, levam à reflexão? E como se dá essa reflexão? (Mf5, A tecnologia e a formação continuada I).

Depois da leitura dos portfólios, mais outros pontos me levaram à reflexão, a saber: Por que se têm dúvidas quanto à formação com relação aos cursos virtuais oferecidos? O que seria importante em cursos de formação contínua virtuais? Quais as contribuiçōes deste curso de formação sob as perspectivas da prática do teletandem e das aulas presenciais / videoconferência? (MF5, A tecnologia e a formação continuada II).

Apesar dos títulos atribuídos aos fóruns (A tecnologia e a formação continuada I e II), apenas $A$ tecnologia e a formação continuada II teve suas perguntas norteadoras diretamente vinculadas ao tema que lhe era subjacente (tecnologia e formação docente continuada), como demonstra a proposta de discussão elaborada para esse fórum no Quadro 2, acima.

A falta de alinhamento entre o tema do debate e a proposta norteadora, muitas vezes materializada sob a forma de questionamento, causa estranhamento e pode levar os cursistas a postarem informações que não sejam as esperadas pelo mediador e, ainda, pode prejudicar a avaliação do rendimento desses cursistas.

O quinto fórum postado na plataforma Teleduc, que apresentaremos a 
seguir, intitulou-se Experiências de "quebra de gelo" e sua postagem teve como objetivo fechar as reflexões iniciadas durante o segundo encontro presencial acerca dos acordos iniciais para o gerenciamento do desenrolar das interaçôes virtuais no teletandem.

A proposta deste fórum visa explorar a visão dos participantes do curso acerca da necessidade, por eles evidenciada, de se enviar e-mails explicitando aspectos relacionados às expectativas, às necessidades e às possibilidades das interações entre os pares interagentes:

Vcs [vocês] concordam que a referida transposição de uma situação da vida real (encontro presencial) para o virtual (teletandem), citada durante nosso segundo encontro, requer troca de e-mails com função de aproximação, baixar o filtro afetivo, quebrar o gelo? Qual a relevância desses e-mails? (Mm3, Experiências de 'quebra de gelo').

Conforme as transcrições dos encontros presenciais, notamos que a proposta foi baseada na percepção de que, para os participantes do curso de formação continuada Formação do Professor para o Ensino/Aprendizagem de Linguas Estrangeiras em Tandem, era importante (ou necessário) que houvesse troca de e-mails mais abundante antes da primeira interação de teletandem. ${ }^{7}$ Segundo os cursistas, essa atitude ajuda a amenizar o acanhamento e a insegurança que eles sentem antes da primeira interação com seus parceiros uruguaios de teletandem, conforme demonstram, a seguir, as postagens extraídas do fórum de dois participantes deste estudo:

Os e-mails são uma forma de 'quebrar o gelo' com certeza!! Pelo primeiro contato já é possível ter uma ideia do seu parceiro e a aproximação fica

\footnotetext{
${ }^{7}$ A prática de teletandem consiste na colaboração entre aprendizes de línguas para que um "ajude" o parceiro a aprender sua língua nativa ou de proficiência. Por meio do uso de ferramentas de comunicação multimodais (vídeo, som e texto) como o Skype e WLM, aprendizes realizam encontros regulares para praticar a língua alvo com o(a) parceiro(a). Esse contexto de aprendizes baseia-se nos princípios da aprendizagem em tandem: autonomia, reciprocidade e uso separado das línguas (TELLES, 2009). Para os aprendizes, a comunicação por meio de mensagens de e-mail ocorre, entre outros objetivos, para estabelecer os primeiros contatos, acordos, agendar os encontros virtuais, mudanças, enviar textos, etc. As discussões iniciadas no encontro presencial tornaram-se tópico de um fórum de discussão devido à complexidade das funçôes das mensagens de email no contexto teletandem, principalmente antes do estabelecimento do primeiro contato com áudio e vídeo entre os aprendizes.
} 
mais fácil. Neste contato já ficam estabelecidas as regras que garantirão o sucesso dos futuros 'encontros'. (PA7, Experiências de 'quebra de gelo').

Eu acredito que sim, que os e-mails são como uma transposição da vida real para o virtual, pois não é comum alguém 'ter um encontro mais íntimo' com outra pessoa quando acaba de conhecê-la. Os e-mails seriam aqueles encontros mais casuais, em que conhecemos o outro, as suas reais intençôes... para depois partirmos para algo mais íntimo, que no teletandem é 'mostrar a cara'. (PA6, Experiências de 'quebra de gelo').

Outro fórum que merece nossa atenção é o intitulado Autonomia. Esse fórum foi, também, elaborado com base em um encontro presencial e difere dos demais por trazer um trecho transcrito do livro Pedagogia da Autonomia (FREIRE, 1996):

Estive lendo muitas coisas interessantes sobre autonomia e gostaria de compartilhar, para que pudéssemos refletir sobre nossa própria autonomia. Vou expor o trecho que extraí de Pedagogia da Autonomia: 'Ninguém é autônomo primeiro para depois decidir. A autonomia vai se construindo na experiência de várias, inúmeras decisões, que vão sendo tomadas (...). A autonomia, enquanto amadurecimento do ser para si é processo, é vir a ser. Não ocorre em data marcada. É nesse sentido que uma pedagogia da autonomia tem de estar centrada em experiências estimuladoras da decisão e da responsabilidade, vale dizer, em experiências respeitosas da liberdade. (FREIRE, 1996, p.107)' O que podemos depreender dessa percepção de autonomia? Como podemos relacionar tal percepção a nossas experiências no Teletandem e no Teleduc? (Mm3, Autonomia).

Essa proposta de discussão se caracteriza por ser altamente diretiva. Ao trazer em si um excerto de grande valor acadêmico, ela pode ter influenciado a maneira como os participantes do curso elaboraram suas postagens no fórum sobre autonomia, inibindo postagens que contivessem um teor contrário ao do excerto que havia sido exposto na proposta do debate.

Os exemplos abordados serviram para que se tivesse uma amostra das estratégias exploradas por mediadores mestrandos $(\mathrm{Mm})$ e professores doutores (Mf), mediante a necessidade de se introduzir um tema para debate no ambiente de fóruns virtuais dessa plataforma pedagógica.

Notamos, com essa breve leitura acerca das maneiras utilizadas para a introdução de um debate no espaço dos fóruns, que os mediadores $\mathrm{Mf}$ e 
Mm do curso Formação de Professores para o Ensino/Aprendizagem de Linguas Estrangeiras em Tandem, subsidiado pela plataforma TelEduc, fizeram uso de diferentes abordagens, ou estratégias ${ }^{8}$ de postagem:

\section{QUADRO 3}

Observaçōes sobre abordagens utilizadas nas propostas de debate nos fóruns.

\begin{tabular}{|c|c|}
\hline Fórum & Observação sobre abordagem utilizada \\
\hline $\begin{array}{l}\text { 1. Um teletandem para } \\
\text { meus alunos }\end{array}$ & \multirow{2}{*}{$\begin{array}{l}\text { Postam-se diretrizes sobre o funcionamento dos fóruns, tanto instruindo os } \\
\text { participantes sobre como devem interagir nesse espaço de debate, quanto } \\
\text { instruindo acerca do que devem debater. }\end{array}$} \\
\hline $\begin{array}{l}\text { 2. Minhas experiências de } \\
\text { Teletandem }\end{array}$ & \\
\hline 3. Refletir e Compartilhar & $\begin{array}{l}\text { Além das diretrizes constatadas nos dois primeiros fóruns, usa-se a expressão } \\
\text { pergunta-chave, o que enfatiza o tema sobre o qual se deve debater. }\end{array}$ \\
\hline 4. Acordos & $\begin{array}{l}\text { Uso de sequência de perguntas abertas, com o intuito de explorar o tema dos } \\
\text { acordos feitos (ou não) entre parceiros de teletandem; a grande quantidade } \\
\text { de perguntas, por um lado, demonstra que o mediador quer explorar vários } \\
\text { aspectos do assunto proposto, mas por outro lado pode confundir o cursista. }\end{array}$ \\
\hline $\begin{array}{l}\text { 5. E-mails para "quebra } \\
\text { de gelo" }\end{array}$ & $\begin{array}{l}\text { Uso de pergunta fechada de opinião (do tipo que a resposta pode ser sim ou } \\
\text { não), seguida de outras perguntas mais abertas e embasadas nas discussóes do } \\
\text { encontro presencial, demonstrando a intenção do mediador de explorar vários } \\
\text { aspectos referentes ao tema do fórum. }\end{array}$ \\
\hline 6. Autonomia & $\begin{array}{l}\text { Proposta de debate que apresenta excerto de livro em sua redação, apresentada } \\
\text { neste estudo como altamente diretiva. }\end{array}$ \\
\hline $\begin{array}{l}\text { 7. A tecnologia e a forma- } \\
\text { ção em serviço I }\end{array}$ & \multirow{2}{*}{$\begin{array}{l}\text { Trazem perguntas embasadas em questionamentos provenientes da leitura dos } \\
\text { portfólios dos participantes de pesquisa. }\end{array}$} \\
\hline $\begin{array}{l}\text { 8. A tecnologia e a forma- } \\
\text { ção em serviço II }\end{array}$ & \\
\hline 9. Experiência Intercultural & \multirow[b]{2}{*}{$\begin{array}{l}\text { Trazem perguntas sobre a percepção dos cursistas acerca dos fenômenos } \\
\text { focalizados. }\end{array}$} \\
\hline $\begin{array}{l}\text { 10. Por que algumas par- } \\
\text { cerias "dão certo" e outras } \\
\text { não? }\end{array}$ & \\
\hline
\end{tabular}

Fonte:Elaborado pelas autoras.

Como o curso foi semipresencial, nota-se que alguns debates foram acordados primeiro presencialmente e, em seguida, tiveram sua proposta feita na plataforma virtual, com alguns direcionamentos das possibilidades de interação no espaço do fórum, como mostram os excertos extraídos de Um teletandem para meus alunos e Minhas experiências de Teletandem.

\footnotetext{
${ }^{8}$ Neste artigo, abordagens e estratégias são utilizadas como sinônimos. Entendemos que, das abordagens dos mediadores é que depreendemos as estratégias, ou as suas estratégias se materializam na forma como abordam os temas e dirigem-se aos cursistas.
} 
Outros debates tiveram sua proposta feita de modo mais direto e simples, assumindo a forma de um ou vários questionamentos. Eventualmente, um formador explicitava se tais questionamentos eram embasados nos materiais elaborados e postados pelos participantes do curso.

Houve até mesmo um exemplo de postagem em que se fez uso de excerto extraído de obra publicada, como o exemplo do fórum sobre autonomia. Uma proposta como essa pode ser entendida como mais diretiva, embora a intenção expressa por $\mathrm{Mm} 3$, mediador responsável pela elaboração da proposta de debate, tenha sido a de "compartilhar" uma leitura a fim de suscitar "reflexão".

Dessa forma, pudemos constatar que houve muitas possibilidades de se abordar os temas de debate dos fóruns virtuais propostos. Além disso, pudemos avaliar as características dessas propostas. Tais reflexões são consideradas e embasam a elaboração de um quadro reflexivo sobre estratégias de gerenciamento de fóruns em plataformas virtuais de aprendizagem, apresentado na última seção deste trabalho.

\subsection{Sobre as abordagens utilizadas por formadores mediadores para intervir durante os debates dos fóruns}

Ainda perseguindo o objetivo de explorar estratégias de mediação que podem ser utilizadas em fóruns virtuais e refletir sobre estratégias de gerenciamento desses debates, damos continuidade à análise elencando exemplos de como foram feitas as intervenções dos mediadores (Mm e Mf) ao longo das discussões.

Ao nos depararmos com o corpus referente aos fóruns do curso Formação do Professor para o Ensino/Aprendizagem de Linguas Estrangeiras em Tandem, encontramos, nas abordagens feitas por mediadores e formadores, similaridades que permitem o agrupamento de algumas dessas produçôes em: (a) perguntas que buscam uma maior elucidação sobre as postagens dos participantes do curso; (b) comentários e questionamentos provocativos, que desafiam os participantes do curso a refletirem sobre a maneira como expressaram seus posicionamentos ao longo dos debates; (c) elogios; (d) dicas e exposição de experiências pessoais; (e) discussões entre os próprios formadores, em que alguns pontos de vista pessoais sobre os temas debatidos nos fóruns são explicitados e, assim, compartilhados com os participantes do curso.

Os primeiros exemplos a serem elencados trazem em si algumas amostras de perguntas que buscam uma maior elucidação acerca de 
informações que não foram consideradas claras ou completas nas postagens dos participantes do curso (PA e PS):

Eu e meu par fizemos acordos sobre os temas mais interessantes para os nossos encontros e Tb [também] sobre horários. (PS12, Acordos).

Cara PS12, Acordo sobre os temas que tratarão foi o único que vocês fizeram? Se, sim, quais foram esses temas? Poderíamos saber? Outra pergunta que me inquieta: por que os acordos sobre os temas e não sobre outras coisas? Os temas estão ligados aos objetivos de cada um, ou se trata de uma simples seleção de temas, para não ficar sem o que falar? Desculpe-me se estou muito 'perguntadeiro', mas essas escolhas e decisōes são muito importantes para nós que estamos estudando o teletandem e suas parcerias. (Mf1, Acordos).

A postagem de PS12 acerca dos acordos feitos entre ele e seu par interagente ao longo das sessões de teletandem é muito sucinta, elenca apenas os temas das próprias interações (os assuntos sobre os quais o par de interagentes conversaria) e os horários em que essas mesmas interaçóes deveriam ocorrer como pontos que evocaram a necessidade de acordos durante a parceria.

Com a intenção de problematizar a temática dos acordos e com a clara exposição de uma justificativa para tal (“(...) essas escolhas e decisões são muito importantes para nós que estamos estudando o teletandem e suas parcerias"), o mediador Mf1 expóe os questionamentos que o deixaram "inquieto" após a leitura da postagem de PS12.

Cabe ressaltar aqui que PS12 foi o primeiro participante a postar suas observações acerca dos acordos que teria feito para gerenciar seu aprendizado ao longo da parceria em teletandem.

Assim, após essas postagens, outros cursistas que tiveram o cuidado de ler o conteúdo do fórum antes de expor seu posicionamento puderam analisar o feedback de Mf1 a PS12 e utilizá-lo como um direcionamento a mais acerca do tipo de postagem que se esperava no contexto desse fórum.

O que ilustra essa observação é a postagem de outro participante do curso, a qual se seguiu após a intervenção de Mf1, iniciada pelo trecho "Conversamos não somente em relação aos horários, mas também...":

Conversamos não somente em relação aos horários, mas também se por acaso houver algum imprevisto no dia, tentar deixar uma mensagem off- 
line pro parceiro avisando que vai se atrasar ou não vai poder comparecer. Também, outro tópico que me pareceu bastante relevante foi a maneira de como vamos abordar um ao outro no momento da correção... (PS15, Acordos).

A seguir, temos outro trecho extraído do mesmo fórum, em que um participante menos atento, PS13, incorre na mesma inadequação, diz que as negociações visam apenas temas e horários. Mas, desta vez, Mf1 se mostra mais sucinto em suas colocaçôes, apenas questionando acerca de quais temas específicos PS13 e seu interagente de teletandem decidiram abordar durante suas interações e frisa "Isso nos interessa":

Minha interagente e eu combinamos os dias da interação e o assunto escolhido. Ela me perguntou sobre o que gostaria de saber e assim estamos interagindo. (PS13, Acordos)

Oi PS13. Ah... mas o quê exatamente você gostaria de saber??? Isso nos interessa. Você poderia nos dizer o que disse à sua parceira? Obrigado! (Mf1, Acordos)

No fórum intitulado Experiência de "quebra de gelo" Mm3, por sua vez, dá outro exemplo de pergunta motivada pela necessidade de uma maior elucidação acerca do assunto exposto no debate:

Estou de acordo é muito difícil esse primeiro encontro da mesma forma que a primeira aula, o primeiro beijo etc. Temos que 'causar uma boa impressão'. (PS12, Experiências de 'quebra de gelo').

O que é necessário para causar essa 'boa impressão'? (Mm3, Experiências de 'quebra de gelo').

Observe que PS12 utiliza a expressão "causar uma boa impressão" que, embora comum entre nós brasileiros, é vaga, dotada de carga semântica muito subjetiva, especialmente em um ambiente em que se discute a importância do cerimonial em forma de e-mails que, para o interagente brasileiro, deve preceder a prática do teletandem.

Por isso, era grande a necessidade de se perguntar o que seria necessário (na ótica de um interagente brasileiro) para causar uma 'boa impressão' já nas trocas de mensagem que antecedem a primeira interação virtual, que deve 
ser síncrona, com recursos audiovisuais, com todos os quesitos típicos das interaçôes de teletandem e, dentre eles, o imprescindível: o outro, o falante competente na língua estrangeira a qual eu me disponho a aprender e a quem eu ajudarei a aprender a minha língua materna (ou outra língua na qual eu seja competente). Assim, o mediador faz uso de uma expressão utilizada pelo próprio aprendiz, para chamar sua atenção para a necessidade de reflexão sobre as diferentes possibilidades semânticas e práticas que ela pode evocar.

A seguir, apresentamos um exemplo daquilo que definimos como comentários e questionamentos provocativos, que desafiam os participantes do curso a refletirem sobre a maneira como expressaram seus posicionamentos ao longo dos debates.

No trecho subsequente, extraído do fórum Um teletandem para meus alunos, Mf7 não está buscando a elucidação de uma declaração ambígua feita por um dos participantes de pesquisa. O que esse mediador faz é provocar a reflexão dos participantes do fórum, dentre eles a própria professora-cursista PS13, acerca da postura pedagógica que tais participantes planejam assumir no caso de chegarem a exercer a oferta do teletandem aos seus alunos dos CELs:

Há alunos com muita vontade de aprender a língua de uma maneira mais rápida; alguns deles destoam do resto da sala, com um ritmo intenso e facilidade na aprendizagem. Esses alunos seriam meus escolhidos para participarem do projeto. (PS13, Um teletandem para meus alunos).

Meu papel aqui é o de advogada do diabo: e não seria o Teletandem justamente algo que poderia estimular interesse em alunos desinteressados ou que tardam a aprender? Quer dizer: Só se aprende em sala de aula e "depois" se usa a língua? Se conversa com alguém da sua idade porque gosta de aprender a língua ou se começa a gostar porque se tenta falar? A língua se aprende falando? Se aprende estudando? Um abraço da advogada do diabo. (Mf7, Um teletandem para meus alunos).

No exemplo supracitado, Mf7 se nomeia "advogada do diabo" e, em uma evidente postura de contestação, expõe um questionamento problematizador, desafiando os participantes dos fóruns a repensarem seus planos futuros. Esse questionamento suscita o estranhamento desses participantes e os ajuda a refletir criticamente sobre as razóes que os estavam conduzindo a assumir uma postura mais excludente com relação à oferta do teletandem. 
Em postagem seguinte à colocação de Mf7, PA7, outro participante de pesquisa, demonstra que as colocações que o antecederam o levaram à reflexão e à mudança de posicionamento:

$\mathrm{Li}$ as respostas do fórum e gostei bastante dos questionamentos apresentados na mensagem da 'advogada do diabo'. Inicialmente também pensei em escolher alguns alunos, principalmente pelo acesso aos computadores, mas também pela responsabilidade/interesse em relação ao projeto. Depois de refletir, acredito que a oportunidade deveria ser aberta a todos para que os que se interessassem e/ou se adaptassem ao sistema pudessem participar. Como foi dito pela ((Mf7)) no encontro presencial, o teletandem só funciona bem quando não é imposto. Um aluno desinteressado na sala de aula poderia sentir-se mais motivado e livre para falar a língua alvo em um 'ambiente privado/informal' com um 'colega' de sua idade, sem, talvez, o medo de errar diante de um professor. (PA7, Um teletandem para meus alunos).

Para PA7, o medo de arriscar-se pode ser um dos fatores que acentuam o desinteresse dos alunos pela interação em sala de aula e o teletandem. Segundo a percepção desse participante de pesquisa, então, proporcionaria a esse tipo de aluno uma chance de arriscar-se na língua-alvo.

Provavelmente, se não houvesse a interferência provocadora de Mf7, "advogada do diabo", os professores continuassem enxergando o teletandem como uma prática possível apenas para os alunos mais interessados e mais dedicados, excluindo os demais aprendizes de seus planejamentos para o futuro. Assim, a intervenção problematizadora de Mf7 no fórum suscita mais reflexão sobre a questão.

A seguir, temos um exemplo do uso de elogio como estratégia gerenciadora do debate dos fóruns. Nesse exemplo, o elogio é feito por um mediador (Mf7) e se destina a todos os indivíduos que participam do debate.

Infere-se que o intuito do formador ao introduzir o elogio seja o de motivar esses mesmos participantes para o debate de novos aspectos do tema proposto no fórum: as experiências interculturais proporcionadas pela prática do teletandem:

Oi, pessoal. É muito interessante ler as respostas de vocês relatando o quanto a experiência intercultural tem sido válida dentro do teletandem. Gostaria de acrescentar uma nova reflexão aqui a partir de uma definição de competência intercultural, que seria a capacidade e habilidade de entrar em outras culturas e se comunicar de maneira eficaz e apropriada, 
estabelecer e manter relacionamentos e desempenhar tarefas com pessoas de outras culturas. Como vocês acham que a relação de teletandem os ajuda a desenvolver tal competência e como o professor pode auxiliar os alunos no desenvolvimento de tal competência em sala de aula? (Mf2, Experiência intercultural)

Observe que, logo após o elogio, Mf2 introduz novos elementos ao debate, como uma definição para interculturalidade ("Gostaria de acrescentar uma nova reflexão aqui a partir de uma definição de competência intercultural...") e, a seguir, propõe um novo questionamento ("Como vocês acham que a relação de teletandem os ajuda a desenvolver tal competência e como o professor pode auxiliar os alunos no desenvolvimento de tal competência em sala de aula?").

Os indícios textuais demonstram que o elogio é utilizado como elemento persuasivo, cujo papel é seduzir (buscar o envolvimento) os participantes do fórum a participarem desse novo desdobramento dado ao debate.

De modo similar, justificativas como as já citadas: "essas escolhas e decisões são muito importantes para nós que estamos estudando o teletandem e suas parcerias" e "Isso nos interessa", dadas por Mf1, também têm uma intenção semelhante a do elogio (motivar o desdobramento do debate acerca de temas não muito bem abordados), mas, embora ambas as estratégias sejam diretivas, o poder persuasivo dos elogios como estratégia de gerenciamento dos fóruns demonstra um maior esforço em influenciar seus participantes, e sem a clareza proporcionada pelas justificativas de Mf1.

As postagens extraídas dos fóruns a seguir demonstram como ocorreu a troca de experiências entre formador (Mf1) e participante do curso de formação continuada (PS15).

No trecho que se segue, PS15, após postar suas contribuições para o debate acerca dos acordos que são feitos ao longo da parceria em teletandem, recebe uma contribuição de Mf1 acerca do uso do talk and write, ${ }^{9}$ como ferramenta que auxilia o exercício das anotações durante as interaçôes colaborativas de teletandem e, consequentemente, diminui a necessidade de correções ao par interagente durante a prática conversacional:

\footnotetext{
${ }^{9} \mathrm{O}$ Talk and Write é um aplicativo que associado ao skype proporciona o uso de uma espécie de quadro colaborativo, onde ambos os parceiros interagentes de teletandem fazem suas anotações ao longo das interações. Para maiores informações: <http://www. talkandwrite.com>. Acesso em: 30 jul. 2014.
} 
Caro ((PS15)), Quanto às correções: a decisão de vocês dois mostra que entendem a língua estrangeira como instrumento de comunicação, pelo menos no primeiro momento. Eu também, quando faço teletandem, gosto de, primeiramente, ouvir O QUÊ a pessoa tem a dizer e em seguida, presto atenção à forma. De qualquer maneira, a forma, para mim, está sempre subjacente, porque uso o TALK \& WRITE para anotações (www.talkandwrite.com). Enquanto meu parceiro fala, vou anotando e ele vai olhando na telinha do TAW enquanto ele fala e enquanto eu vou anotando. Às vezes, eu não preciso dizer nada, porque, quando escrevo a palavra, expressão ou ponto gramatical, ele olha para a tela do TAW e já se autocorrige, continuando o que está falando. Quando minha parceira vacila, eu sempre vou ao socorro e lhe dou a palavra, escrevendo no TAW. Ela olha para a tela e a usa imediatamente. Assim, a palavra nova, ou a dúvida, fica registrada nas anotações do Talk \& Write (TAW). Um abraço. Espero que a dica tenha servido. Estou falando como praticante de teletandem e não como orientador ou pesquisador. Quero compartilhar com você minha experiência. (Mf1, Acordos).

A resposta de PS15 para seu formador (Mf1) é positiva. PS15 agradece a dica de F1 e diz que a informação teve efeitos em sua prática de teletandem, possibilitando a otimização do diálogo ao longo da interação:

((MfI)), A dica do TALK \& WRITE foi bárbara, tivemos uma conversa muito mais proveitosa e fluiu muito melhor, pois quase não tivemos que nos preocupar com a forma, já que com o TALK quase tudo que nos parecia relevante e digno de correção, era esclarecido no ato da fala. Mais uma estratégia [de] correção que já faz parte das nossas interações, abraço... (PS5, Acordos).

Assim, percebemos que a troca de conhecimentos entre formadores e inscritos no curso de formação continuada também foi uma prática pertinente ao espaço do fórum, como espaço destinado à troca de saberes e à construção da aprendizagem.

Outra prática discursiva nos chama a atenção nos fóruns ocorridos na plataforma TelEduc ao longo do curso Formação de Professores para o ensinol aprendizagem em Tandem, os "meta-fóruns", ou seja, as discussões entre os próprios formadores acerca dos temas que deveriam ser abordados nos próprios fóruns.

Nos excertos a seguir, dois formadores (Mf4 e Mf5) discorrem sobre suas percepções acerca da relevância ou não de se abordar a discussão de certos temas nos fóruns de discussão. 
Sabe, pessoal, como participantes do teletandem, acho que precisamos começar a pensar na formação do professor para o ensino do português como LE. Acredito que muitas das dificuldades também estão nessa área (...). (Mf4, A tecnologia e formação de serviço II).

Concordo com você $M f$, com relação à reflexão sobre a formação do professor para o ensino de português como LE, porém, acredito que a necessidade de reflexão seja mais geral, no sentido de formação de professores, e talvez isso esteja relacionado ao processo de ensino/ aprendizagem pelo qual passamos, aquilo que trazemos, normalmente, éramos muito passivos como alunos, esperávamos mais do que fazíamos... Isso se reflete quando somos profissionais, o medo do que é novo, porque é mais fácil lidar com o que já conhecemos... Não sei, é importante refletir muito sobre a formação seja pré-serviço ou continuada. (Mf5, A tecnologia e formação de serviço II)

Sim, Mf5, vc tem razão. Nossas experiências passivas como alunos são reforçadas na formação inicial, já que os cursos de formação ainda são bastante tradicionais, no sentido de darem tudo pronto aos futuros professores, que custam a deixar a posição de alunos; nós mesmas passamos por isso, né? (...) (Mf4, A tecnologia e formação de serviço II)

Para Mf4 existe a necessidade de se pensar o ensino de Língua Portuguesa como língua estrangeira de forma mais sistematizada, uma vez que essa é uma das possibilidades de prática de ensino que estão figuradas dentre o leque de possibilidades de ensino e de aprendizagem abarcados pelo teletandem.

Deve ser ressaltado, também, que dentre os participantes de pesquisa, nenhum citou ter formação para ou experiência no ensino de PLE. Contudo, todos tiveram que exercer esse tipo de ensino em contexto mediado pelo computador, com a prática do teletandem.

Embora uma proposta válida, Mf5 discorda de seus colegas, alegando que "a necessidade de reflexão" talvez "seja mais geral", devendo abordar questôes de ensino e de aprendizagem que perpassem pelas experiências dos participantes do curso, tanto anteriores à formação acadêmica, quanto posteriores a ela.

Finalmente, Mf4 parece acatar o direcionamento sugerido pelo colega, Mf5, compartilhando do mesmo ponto de vista deste último e justificando que as experiências vivenciadas pelos professores como alunos podem 
influenciar a prática docente. Embora a discussão entre os formadores sobre o tema não seja uma proposta direta de um novo tema para o fórum, ela leva os participantes do fórum a considerarem um tópico que ainda não havia sido abordado, mas que está ligado às reflexões que se encaminham.

\section{Considerações finais}

Com este recorte feito sobre os tipos de abordagens/estratégias que mediadores (Mf) e ( $\mathrm{Mm}$ ) exerceram ao postarem suas observaçōes, questionamentos, contribuições e interagirem com os participantes dos fóruns, buscamos tecer considerações contextuais desse espaço de interação online, subsidiado pela plataforma TelEduc.

A análise das intervenções dos mediadores nos fóruns nos deu indícios sobre como o papel do mediador, em contexto de fóruns de discussão, materializa-se e o que revela sobre as características da interação nesse contexto.

Observamos, por meio do embasamento teórico e da análise dos dados, que os papéis dos mediadores evidenciam-se por meio do discurso expresso nas postagens dos fóruns de discussão.

Concluímos, dentro dos limites deste estudo, que as postagens de abertura de fóruns têm um potencial para motivar, direcionar e organizar as contribuiçôes dos aprendizes, ampliando ou limitando as possibilidades de participação e interação nesse contexto.

As limitações deste estudo não nos permitem analisar outros aspectos igualmente importantes da mediação em fóruns de discussão online. Destarte, as relações de poder, perfil dos participantes, letramento digital, experiências com contextos virtuais de aprendizagem, características e demandas de diferentes cursos, entre outros, são aspectos que precisam ser considerados em futuras análises, inclusive por uma coleta de dados mais abrangente.

Contudo, um quadro reflexivo sobre estratégias de gerenciamento de fóruns em plataformas virtuais de aprendizagem pode ser proposto, como construto de limitações sócio-históricas, com potencial para ajudar mediadores a refletirem sobre os desafios da mediação em contextos virtuais e assíncronos de debate: 


\section{QUADRO 4}

Tópicos reflexivos sobre mediação em fóruns virtuais.

\section{Refletindo sobre a análise de fóruns em contextos virtuais e assíncronos}

E preciso avaliar a necessidade de familiarizar os participantes do curso com a prática enunciativa pertinente a esse contexto de debates e com o propósito desse espaço (as trocas de conhecimentos) para o curso.

Mesmo que o sentido das propostas de debate não seja o de restringir as possibilidades de interação ou o teor das postagens nos fóruns, essas propostas também farão isso. Da mesma forma, a postagem de um mediador comentando a postagem de um cursista também influenciará (talvez não deterministicamente) nos percursos do debate.

Algumas expressões (como "pergunta-chave") podem reforçar a ideia de que a pergunta que se segue é fundamental para o desenvolvimento das atividades nesse fórum e deve ser respondida nas postagens dos cursistas.

O tema do fórum e o questionamento norteador, caso exista um, devem ter coerência entre si. Usar um tema e propor um questionamento cuja ligação ao tema não seja textualmente evidenciada pode atrapalhar o desempenho dos cursistas.

Em cursos do tipo blended (ou semipresenciais), fóruns podem servir para propor uma reflexão cuja necessidade está baseada em indícios deflagrados no encontro presencial e, assim, pode servir de base para o replanejamento desses encontros.

Em cursos onde há vários mediadores atuando em conjunto é necessário que as diretrizes e as formas de intervenção sejam pedagogicamente planejadas e compartilhadas com antecedência. Contudo, o mediador pode ser surpreendido pelos rumos que um debate assume; assim, elucidar as razóes pelas quais uma dada proposta foi alterada (e até mesmo refletir sobre isso de modo compartilhado, com ênfase na aprendizagem) pode ser positivo para os cursistas.

Fonte:Elaborado pelas autoras.

É importante ressaltar que, diferentemente de alguns estudos apontados na fundamentação teórica deste trabalho - que traziam ou reflexões sobre a natureza das interações em fóruns virtuais de debate, como Barros e Souza (2011) e Salmon (2009); ou contribuições sobre as competências esperadas de um mediador (BAWANE \& SPECTOR, 2009) - o presente estudo buscou refletir sobre estratégias de gerenciamento de fóruns com base em dados de um estudo de caso de orientação interpretativista. Assim, o artigo pode abordar a participação do mediador em fóruns de discussão, abrangendo essas diferentes dimensões: a dimensão das características das interações em fóruns virtuais, das competências, papéis e das estratégias/ abordagens dos mediadores no gerenciamento de debates.

As abordagens analisadas nos permitiram refletir, de forma ampla, sobre como os papéis dos mediadores se materializam nas relações com os aprendizes. Dentro dos limites deste estudo, pudemos observar, com maior evidência, alguns indícios dos papéis pedagógico, social e administrador (BAWANE \& SPECTOR, 2009). Por outro lado, entendemos que esses e os demais papéis e competências elucidados no embasamento teórico estão interligados e subjazem todo o processo de aprendizagem e interação 
em contextos virtuais de aprendizagem, com maior ou menor evidência, dependendo das características, relações pedagógicas, propostas, período, etc. de um curso.

Com as orientações apresentadas no quadro acima esperamos contribuir com a elucidação de diferentes desdobramentos e complexidades da interação em contexto de fóruns online e da prática de mediação pedagógica nesse ambiente assíncrono de aprendizagem.

Assim, finalizamos a análise proposta e esperamos que futuros estudos possam ser desenvolvidos para contribuir para o desenvolvimento de contextos e ferramentas virtuais de aprendizagem, e para a promoção de práticas mais autônomas e reflexivas de aprendizagem.

\section{Referências}

BACHMANN, G.; DITTLER, M.; LEHMAN, T.; GLATZ, D.; RÖSEL, F. Das Internetportal LearnTechNet der Uni Basel: Ein Online Supportsystem für Hochschuldozierende im Rahmen der Integration von E-Learning in die Präsenzuniversität. In: HAEFELI, O.; BACHMANN, G.; KINDT, M. (Org.). Campus 2002 - Die Virtuelle Hochschule in der Konsolidierungsphase, Tagungsband der GMW Jahrestagung 2002, Münster: Waxmann Verlag, p.87-97, 2002.

BARAN, E.; CORREIA, A.P. Student-led facilitation strategies in online discussions. Distance Education, v.30, n.3, p.339-361, 2009.

BARROS, J. C.; SOUZA, P.N. Práticas discursivas de uma tutora em fóruns de discussão online. Veredas On Line - Atemática. PPG Linguística/ UFJF - Juíz de Fora, p.383-397, 2011. Disponível em: <http://www.ufff.br/revistaveredas/ files/2011/05/ARTIGO-271.pdf>. Acesso em: 30 jul. 2014.

BAWANE, J. Y.; SPECTOR, J. M. Prioritization of online instructor roles: implications for competency-based teacher education programs. Distance Education, v.30, n.3, p.383-397, 2009.

BERGE, Z. L. Facilitating computer conferencing: Recommendations from the field. Educational Technology, v.15, n.1, p.22-30, 1995.

BREMER, C. Lessons learned: Moderation und Gestaltung netzbasierter Diskussionsprozesse in Foren - Erfahrungen aus virtuellen Konferenzen und Gestaltungsoptionen von Foren im eLearning. In: KERRES, M.; VOSS, B. (Org.). Digitaler Campus. Vom Medienobjekt zum nachhaltigen Medieneinsatz in der Hochschule. Münster, 2004, p.191-201. 
CHAIKLIN, Seth. The zone of proximal development in Vygotsky's analysis of learning and instruction. In: KOZULIN, A.; GINDIS, B.; AGEYEV, V. S.; MILLER, S. M. (Org.). Vygotsky's educational theory in cultural context.Cambridge University Press, 2003.

FILK, C. Synchronizitätsgradebeimkollaborativen e-Learning: einigeHypothesen und Perspektiven. In: WAGNER, E.; KINDT, M. (Org.). Virtueller Campus Szenarien - Strategien - Studium.Münster, 2001.

FREIRE, P. Pedagogia da autonomia. São Paulo: Paz e Terra, 1996.

FRANCISCO, D. J.; MACHADO, G. J. C. Sociedade, EAD, inclusão digital e formação de professores. Revista Iberoamericana de Educación, p. 01 - 13, [2 (ver p.3)004?]. Disponível em: <http://www.rieoei.org/deloslectores/1172Francisco. pdf>. Acesso em: 30 jul. 2014.

FUNO, L. B. A. Teletandem: um estudo sobre identidades culturais e sessōes de mediação da aprendizagem. Em elaboração. Tese (Doutorado em Estudos Linguísticos)Instituto de Biociências, Letras e Ciências Exatas, UNESP, São José do Rio Preto. GLESNE, C.; PESHKIN, A. Becoming Qualitative Researchers - An Introduction. New York: Longman, 1992.

HOUAISS: Dicionários eletrônico da lingua portuguesa. Versão 2.0a, Abril de 2007. KLEIN, J. M.; SPECTOR, J.M.; GRABOWSKI, B.; DE LA TEJA, I. Instructor competencies: Standards for face-to-face, online, and blended settings. Greenwich, CT: Information Age, 2004.

MILL, D. Reflexões sobre a formação de professores pela/para educação a distância na contemporaneidade: convergências e tensōes. In: DALBEN, A.I.L.F. [et al.]. (Org.). Convergências e tensôes no campo da formação e do trabalho docente. Belo Horizonte: Autêntica, 2010, p.295-314.

MITCHELL, R; MYLES, F. Sociocultural Perspectives on Second Language Learning. In:Second Learning Theories. London: Arnold, 1998.

MOITA LOPES, L. P. Pesquisa interpretativa em lingüistica aplicada: a linguagem como condição e solução. D.E.L.T.A., 10/2, 329-338, 1994.

PAULSEN, M. P. Moderating educational computer conferences. In: BERGE, Z.L.; COLLINS, M.P. (Eds.). Computer-mediated communication and the on-line classroom in distance Education. Cresskill, NJ: Hampton Press, 1995, p.81-104.

SALMON, G. E-moderation strategies in educational contexts.PowerPoint lecture, University of Leicester, 2009. Disponível em: <http://www2.le.ac.uk/projects/oer/ oers/beyond-distance-research-alliance/bdra-e-moderation-e-tivities-and-the-5stage-model-1>. Acesso em: 30 jul. 2014. 
STAKE, R. E. The Art of Case Study Research. London, New Delhi: SAGE Publications, 1995.

TELLES, J. A. (Org.). Teletandem: um contexto virtual, autônomo e colaborativo para aprendizagem de linguas estrangeiras no século XXI. Campinas: Pontes Editores, 2009. VYGOTSKY, L. S. A formação social da mente. São Paulo: Martins Fontes, 1984.

Data de submissão: 01/08/2014. Data de aprovação: 23/10/2014. 
